\title{
Deficits in emotion regulation strategies among problematic and pathological gamblers in a sample of vocational school students
}

\author{
SVENJA ORLOWSKI*, ANJA BISCHOF, BETTINA BESSER, GALLUS BISCHOF and HANS-JÜRGEN RUMPF \\ Department of Psychiatry and Psychotherapy, University of Lübeck, Lübeck, Germany
}

(Received: March 7, 2018; revised manuscript received: October 30, 2018; accepted: November 24, 2018)

\begin{abstract}
Background and aims: Deficits in emotion regulation (ER) are associated with mental disorders. To date, there are hardly any studies focusing on the role of ER strategies in the context of gambling behavior. The aim of this study was to investigate the association between specific ER strategies and pathological as well as problematic gambling in a proactively recruited sample. Methods: A large and unselected sample $(n=4,928)$ has been screened proactively and systematically in vocational schools. We assessed the Affective Style Questionnaire to measure ER strategies and the Stinchfield questionnaire for assessing problematic and pathological gambling. Associations were investigated with linear and multinomial logistic regression analyses. Results: The analyses showed a significant negative correlation between the subscales "Adjusting" and "Tolerating" and the Stinchfield sum score. Lower scores on these subscales were associated with a higher number of endorsed Stinchfield items. A lower score on the ER strategies "Adjusting" [conditional odds ratio $(\mathrm{COR})=0.95$, confidence interval $(\mathrm{CI})=0.91-0.99]$ and "Tolerating" $[\mathrm{COR}=0.95$, $\mathrm{CI}=0.92-99]$ led to a higher chance of being classified as a pathological gambler. In problematic gambling, on a subthreshold level, only "Tolerating" turned out to be significant $[\mathrm{COR}=0.96, \mathrm{CI}=0.93-0.99]$. Discussion and conclusions: For the first time, deficits in specific ER strategies were identified as independent risk factors for problematic and pathological gambling in a large and proactively recruited sample. ER skills, especially acceptancefocused strategies, should be considered in prevention and psychotherapy.
\end{abstract}

Keywords: pathological gambling, problematic gambling, emotion regulation strategies, risk factor, proactive recruitment, unselected sample

\section{INTRODUCTION}

In recent years, the regulation of emotions has received increased interest in the context of psychotherapy and clinical-psychological research of mental health (Aldao, Nolen-Hoeksema, \& Schweizer, 2010; Berking \& Wupperman, 2012; Gross \& John, 2003). The number of publications in the field of emotion regulation (ER) and psychopathology has grown enormously. According to the definition by Gross (1998), ER refers to the process by which people influence which emotion they have, when they have them, and how they experience and express these emotions.

In accordance with the Process Model of ER (Gross \& Thompson, 2007), antecedent-focused ER strategies and response-focused ER strategies can be distinguished. Antecedent-focused strategies refer to the subject's behavior before the emotion response tendencies have become fully activated, such as situation selection, attention control, or cognitive concepts regarding the emotional situation (Gross \& John, 2003; Gross \& Thompson, 2007). Responsefocused strategies, such as modification of the emotional response, refer to behavior that occurs after emotional response tendencies have already been generated and the emotion is underway (Gross \& John, 2003). Three different styles of ER strategies have been identified consistently: concealing or suppression, adjusting or reappraisal, and tolerating (Hofmann \& Kashdan, 2010).

Processes regulating emotions have a high relevance for mental health. The association between the use of dysfunctional ER strategies and psychopathology was described by several studies, and the concept of ER is part of many models of psychopathology (Aldao et al., 2010; Berking \& Wupperman, 2012). These studies demonstrated that people suffering from psychiatric disorders often have difficulties with using functional and adaptive ER strategies (Aldao, Jazaieri, Goldin, \& Gross, 2014; Aldao et al., 2010; Werner \& Gross, 2010).

Although many psychiatric disorders such as the borderline personality disorder (Levine, Marziali, \& Hood, 1997), major depression (Rottenberg, Gross, \& Gotlib, 2005), anxiety disorder (Campell-Sills \& Barlow, 2007), or eating disorders (Bydlowski et al., 2005; Harrison, Sullivan, Tchanturia, \& Treasure, 2010) are associated with deficits in ER, only a few studies have investigated the relevance of ER in substance-related disorders. Theoretical approaches

* Corresponding author: Svenja Orlowski; Department of Psychiatry and Psychotherapy, University of Lübeck, Ratzeburger Allee 160, 23538 Lübeck, Germany; Phone: +49 451500 98759; Fax: +49 451500 98754; E-mail: svenja.orlowski@uksh.de

This is an open-access article distributed under the terms of the Creative Commons Attribution-NonCommercial 4.0 International License, which permits unrestricted use, distribution, and reproduction in any medium for non-commercial purposes, provided the original author and source are credited, a link to the CC License is provided, and changes - if any - are indicated. 
suggest that emotions play an essential role especially in the context of addictive disorders and should be incorporated into models of psychopathology. Khantzian (1985) postulated the self-medication hypothesis of addictive disorders, assuming that people are using drugs to treat their negative emotions, which is one of today's most popular models. In addition, numerous studies suggest that both positive and negative affects play an important role in the development and maintenance of substance-related disorders (Baker, Piper, McCarthy, Majeskie, \& Fiore, 2004; Cheetham, Allen, Yucel, \& Lubman, 2010; Kassel et al., 2007).

A variety of studies showed that, in addictive disorders, specific ER strategies could be observed. In a meta-analysis, Aldao et al. (2010) summarized studies of ER strategies for different psychiatric disorders including addictive disorders. They only found significant positive correlations between substance abuse and the two ER strategies "avoidance" and "rumination." No significant correlations were found regarding further ER strategies, for example, expressive suppression.

Some studies have shown that people with substancerelated disorders reveal deficits in ER compared to healthy controls, for example, in adaptive regulation of emotions and inability to tolerate negative emotions (Berking et al., 2011), strategies of emotional awareness and impulse control (Fox, Axelrod, Paliwal, Sleeper, \& Sinha, 2007; Fox, Hong, \& Sinha, 2008), and rumination (Nolen-Hoeksema, Stice, Wade, \& Bohon, 2007). On the contrary, the ER strategies "suppression of emotions" and "experiential avoidance" seem to be rather dysfunctional strategies (Levin et al., 2012; Wong et al., 2013). In the aforementioned studies, maladaptive ER strategies predicted alcohol consumption during therapy, increased substance-related problems, or relapse.

To date, most of the available studies regarding specific ER strategies and addiction are from the field of substancerelated disorders, mainly based on alcohol-dependent patients. Studies in the field of gambling are scarce. Nevertheless, first studies focusing on pathological gambling looked at ER in general rather than the functional or dysfunctional use of specific ER strategies (Estevez, Jauregui, Sanchez-Marcos, Lopez-Gonzalez, \& Griffiths, 2017; Kapsomenakis, Simos, Konstantakopoulos, \& Kasselimis, 2018; Kopera et al., 2018). It was suggested that ER was predictive of substance-related and behavioral addictions (alcohol and drug abuse, gambling disorder, video game addiction, and problematic Internet use; Estevez et al., 2017).

Only few studies investigate the association between difficulties in specific ER strategies and pathological gambling. Navas, Verdejo-García, López-Gómez, Maldonado, and Perales (2016) explored the differences between gambling disorder patients and healthy controls in gamblingrelated cognitions and use of ER strategies, revealing that gambling disorder patients used "self-blame" and "catastrophizing," but also "positive refocusing," more often than controls. However, the study was limited as the sample consisted only of men. Williams, Grisham, Erskine, and Cassedy (2012) assessed the use of maladaptive and adaptive ER strategies in a sample of pathological gamblers. The study aimed at examining deficits in ER among individuals being treated in a specialist gambling clinic and to compare the use of strategies to a mixed clinical comparison group and a sample of healthy community controls. Findings show that pathological gamblers and patients of the clinical comparison group reported significantly fewer use of the ER strategy reappraisal, a greater lack of emotional clarity, and more impulse-control difficulties than individuals in the healthy control group. Compared to the healthy control group, pathological gamblers reported less emotional awareness. The authors concluded that pathological gamblers have difficulties in the use of various ER strategies, compared to clinical and healthy controls. Despite the valuable information this study provides, there are some limitations. The subjects were treatment-seeking, suggesting a greater awareness of their problems and higher severity of the disorder. Therefore, the results found in this study cannot be generalized. Furthermore, the authors exclusively included pathological gamblers in their study. However, it might be interesting to examine whether disturbed ER occurs in subthreshold cases as well.

Based on the mentioned theoretical assumptions and on the previous research on ER and addiction, the aim of this study was to investigate difficulties in three specific ER strategies in a proactively recruited vocational school sample of individuals with different types of gambling behavior including full-blown gambling disorder as well as subthreshold diagnoses. We hypothesized that a lower use of functional ER strategies and a higher use of maladaptive ER strategies are strongly related to gambling severity. Accordingly, we further hypothesized that pathological and problematic gamblers have more difficulties in the use of functional ER strategies compared to non-problematic gamblers. Less emotional awareness in pathological gamblers (Williams et al., 2012) might indicate problems in emotion recognition. This induces difficulties for adjusting or even tolerating emotions. Together with the findings of increased impulse-control difficulties in pathological gamblers (Williams et al., 2012) and in other addictive behavior (Fox et al., 2007, 2008), pathological gambling might be used as a behavior to relief from emotional tension increases. As concealing emotions might be not functional, we hypothesized that pathological and maybe problematical gamblers increasingly conceal their negative emotions.

\section{METHODS}

\section{Participants and procedure}

This study was part of the project "Migration and gambling: investigation of the development in a longitudinal study" (MIGUEL) conducted with a sample of students of vocational schools in the federal state Schleswig-Holstein (Germany) between July 2016 and March 2017. Data in this study were collected proactively, which means every student in the classroom was approached systematically with questionnaires by trained study staff. The aim of the survey was to screen for subjects eligible for a diagnostic interview on risk and protective factors for problematic and pathological gambling. This analysis focuses on the screening sample. The questionnaires were handed out to the 
participants by trained interviewers in the classroom. Because every student was asked to participate, the data were not preselected. Answering all questions took about 20-30 min. A total of 6,781 participants completed the questionnaire, 63 of the screenings had to be excluded due to insufficient knowledge of the German language or double participation, leaving a sample of 6,718 valid screenings. Of those, 1,790 had missing data in one of the variables that have been included in the analyses as independent variables. These were excluded from the analyses, leaving a final sample of 4,928 valid cases.

\section{Measures}

Gambling. A German translation of the Stinchfield selfreporting questionnaire was utilized for the classification of pathological or problematic gambling (Stinchfield, 2002). Because it had been developed based on DSM-IV, we modified the instrument to fit DSM-5 (American Psychiatric Association [APA], 2013) criteria by removing the "illegal acts" criterion. Later, the questionnaire included 17 items. Every DSM-5 criterion was assessed by two items, except criterion 2 "craving," which was measured with only one item. The instrument is provided with excellent internal consistency in a general population-based sample $(\alpha=.81)$, in a sample of treatment-seeking individuals $(\alpha=.77)$ as well as in the combination of the two samples $(\alpha=.97)$ (Stinchfield, 2002, 2003). In this study, the instrument showed a good internal consistency with Cronbach's $\alpha$ .87. Lesieur and Blume (1987) assessed the convergent validity of the questionnaire with the South Oaks Gambling Scale as reference and proved it with $r=.77(p<.01)$ in the general population-based sample and with $r=.75(p<.01)$ in the sample of treatment-seeking individuals satisfactory. The number of criteria based on DSM-5 criteria were calculated for defining groups (see "Statistical analyses" section).

Emotion regulation. In this study, we decided to use the Affective Style Questionnaire (ASQ; Hofmann \& Kashdan, 2010), which includes three strategies of ER. In addition to the antecedent-focused strategy "Concealing" and the response-focused strategy "Adjusting," the ASQ includes the ER strategy "Tolerating." The questionnaire consists of 20 items measuring individual differences in ER. Each of these three ER strategies is being measured by one subscale: The scale "Concealing" includes eight items regarding avoiding and concealing aspects of emotions (e.g., "I am good at hiding my feelings"). The subscale "Adjusting" includes seven items on skills that influence and modify one's own emotions by cognitive strategies (e.g., "I can avoid getting upset by taking a different perspective on things"). A tolerating or accepting style of dealing with emotions is assessed by the subscale "Tolerating" that refers to a high emotional stress tolerance (e.g., "It's OK to feel negative emotions at times").

In this study, the German version of the ASQ was used. Graser et al. (2012) translated and validated the ASQ with a German sample of students. Based on the results of factor analyses, the authors decided to rearrange two items on the scale "Adjusting." Thus, the German version of the ASQ assessed the ER strategies "Concealing" with nine items,
"Adjusting" with five items, and "Tolerating" with six items. The authors found a satisfactory (to good) internal consistency for the three subscales. Cronbach's $\alpha$ was .84 for "Adjusting," .75 for "Concealing," and .72 for "Tolerating." In our sample, Cronbach's $\alpha$ was .79 for "Adjusting," .79 for "Concealing," and .69 for "Tolerating."

Mental health. The brief questionnaire "Mental Health Inventory" (MHI-5; Berwick et al., 1991) was used to assess mental health. This short instrument consists of five items and was derived from the 38-item Mental Health Inventory. The MHI-5 includes items referring to positive and negative aspects of mental health, and items referring to depression and anxiety (Berwick et al., 1991). With a Cronbach's $\alpha .74$, the internal consistency of the MHI-5 is satisfactory, especially for depression and anxiety (Rumpf, Meyer, Hapke, \& John, 2001). High values refer to a better mental health.

Alcohol use. We used the "Alcohol Use Disorder Identification Test - Consumption" (AUDIT-C) to assess problematic alcohol consumption, alcohol abuse, and alcohol addiction (Bush, Kivlahan, McDonell, Fihn, \& Bradley, 1998). The short version of the AUDIT includes the first three items of the 10 items original test and provides information on drinking amount and frequency. Sensitivity and specificity proved to be good (Reinert \& Allen, 2002). In addition, test-retest reliability was high (Dybek et al., 2006). High values refer to higher alcohol consumption.

\section{Statistical analyses}

To investigate the association between the three ER strategies and gambling, a linear regression analysis was conducted for dimensional analyses first and then multinomial logistic regression analyses for categorical analyses. For the identification of gambling-related problems, a sum score of the Stinchfield questionnaire was calculated. Individuals who fulfilled four or more criteria were classified as pathological gamblers according to DSM-5 (APA, 2013). In addition, we classified a subthreshold category for individuals who did not meet enough criteria for a diagnosis of dependence: Problematic gambling is defined by meeting two or three criteria. The third category was described as non-problematic gamblers who met one criterion or none at all. Based on these definitions, we classified 4,440 individuals as non-problematic gamblers, 285 as problematic gamblers, and 203 as pathological gamblers. According to the hypotheses, we expected lower scores for the ASQ subscales "Adjusting" and "Tolerating" and a higher score for "Concealing" for pathological gamblers compared to non-problematic gamblers, which may already be evident in subthreshold cases of problematic gamblers.

For ER strategies, sum scores of each subscale were calculated to analyze differences on the three subscales of the ASQ (Concealing, Adjusting, and Tolerating). Missing values in the ASQ have been replaced by the series mean. All analyses have been adjusted for sociodemographic characteristics and risk factors. The regression coefficient $[\operatorname{Exp}(B)]$ was interpreted in terms of a conditional odds ratio (COR; Gould, 2000) in all multinomial logistic regression analyses. 
Associations of lower mental health (Aldao et al., 2010; Gross \& Munoz, 1995) as well as alcohol use (Berking et al., 2011) and dysfunctional ER can consistently be found throughout the ER literature. Furthermore, it has been previously shown that male sex and migration proved as risk factors for problematic and pathological gambling behavior (Petry, Armentano, Kuoch, Norinth, \& Smith, 2003) and studies suggest gender differences in the use of ER strategies (McRae, Ochsner, Mauss, Gabrieli, \& Gross, 2008; Nolen-Hoeksema \& Aldao, 2011). Therefore, we checked possible confounding variables by Spearman's correlations in advance. Statistical analyses were performed using IBM SPSS Statistics 22 (Armonk, NY, USA).

\section{Ethics}

The study procedures were carried out in accordance with the Declaration of Helsinki. The local ethics committee of the University of Lübeck approved MIGUEL (reg. no. 16-102). All subjects were informed about the study and the participation was voluntary. Informed consent was not necessary because study participation was anonymous. This procedure was in accordance with the local ethics committee and the Ministry of Education of Schleswig-Holstein.

\section{RESULTS}

\section{Participants' characteristics}

The sample included 4,928 subjects of which $62.8 \%$ $(n=3,096)$ were male and $37.2 \%(n=1,832)$ were female. The mean age was 19.9 [standard deviation $(S D)=3.72$; range $15-52]$ and $20.8 \%(n=1,023)$ of the individuals had a migration background (MB), meaning that either the individuals themselves or at least one of their parents were born outside of Germany.
Analyses for the 12-month prevalence are based on the items of the Stinchfield questionnaire. On average, individuals affirmed $1.22(S D=1.44)$ Stinchfield items in the Stinchfield questionnaire. The 12-month prevalence for pathological gambling ( $\geq 4$ DSM-5 criteria) was $4.1 \%$ ( $n=$ 203; CI $=3.6-4.7)$ and for problematic gambling (2-3 DSM-5 criteria) 5.8\% $(n=285 ; \mathrm{CI}=5.2-6.4)$. The sum score of the DSM-5 criteria was positively correlated with the subscale "Concealing" $(r=.070 ; p<.001)$ and negatively correlated with the subscale "Tolerating" $(r=-.060 ; p<.001)$. There was no correlation with the subscale "Adjusting." An overview of the descriptive statistics of the variables can be found in Table 1 .

\section{Controlling for confounding variables}

The MHI-5 was positively correlated with the ER strategy "Adjusting" $(r=.461 ; p<.001)$ and "Tolerating" $(r=.222$; $p<.001)$. Therefore, a better use of these strategies is associated with better mental health. Furthermore, the analyses yielded a positive correlation between AUDIT-C and the ER strategy "Concealing" $(r=.091 ; p<.001)$ and a negative correlation with "Tolerating" $(r=-.043$; $p=.002$ ), although the correlations were low. The higher the alcohol consumption, the more people concealed their negative emotions and the less they tolerated them.

Concerning sociodemographic characteristics, a Mann-Whitney $U$ test showed significant differences between male and female subjects on the subscales "Concealing" $\left(M_{\text {male }}=30.14, S D=5.92 ; M_{\text {female }}=28.34, S D=6.22\right)$ with $p<.001$ and "Adjusting" $\left(M_{\text {male }}=17.27, S D=4.00\right.$; $M_{\text {female }}=15.17, S D=4.09$ ) with $p<.001$. Furthermore, there were significant differences between subjects with and without $\mathrm{MB}$ for the subscales "Concealing" $\left(M_{\mathrm{MB}}=30.00, \quad S D=6.20 ; \quad M_{\mathrm{NoMB}}=29.23, \quad S D=6.05\right)$ with $p<.001$ and "Tolerating" $\left(M_{\mathrm{MB}}=19.75, S D=4.16\right.$; $\left.M_{\mathrm{NoMB}}=20.67, S D=4.05\right)$ with $p<.001$. Due to these findings, the variables sex, MB, AUDIT-C sum score, and

Table 1. Sample description of the total sample and of the three subgroups

\begin{tabular}{|c|c|c|c|c|}
\hline Feature & Total $(N=4,928)$ & $\begin{array}{c}\text { Non-problematic } \\
\text { gamblers }(n=4,440)\end{array}$ & $\begin{array}{c}\text { Problematic } \\
\text { gamblers }(n=285)\end{array}$ & $\begin{array}{c}\text { Pathological } \\
\text { gamblers }(n=203)\end{array}$ \\
\hline Age $[M(S D)]$ & $19.90(3.7)$ & $19.92(3.8)$ & $19.51(2.7)$ & $20.00(2.8)$ \\
\hline \multicolumn{5}{|l|}{ Gender $[n(\%)]$} \\
\hline Male & $3,096(62.8)$ & $1,798(40.5)$ & $260(91.2)$ & $194(95.6)$ \\
\hline Female & $1,832(37.2)$ & $2,642(59.5)$ & $25(8.8)$ & $9(4.4)$ \\
\hline \multicolumn{5}{|l|}{ Migration background [ $n(\%)]$} \\
\hline Yes & $1,023(20.8)$ & $850(19.1)$ & $92(32.3)$ & $81(39.9)$ \\
\hline No & $3,905(79.2)$ & $3,590(80.9)$ & $193(67.7)$ & $122(60.1)$ \\
\hline Stinchfield sum score $[M(S D)]$ & $1.22(2.4)$ & $0.19(0.4)$ & $2.73(0.8)$ & $7.49(3.1)$ \\
\hline DSM criteria sum score $[M(S D)]$ & $0.43(1.3)$ & $0.06(0.3)$ & $2.44(0.5)$ & $5.60(1.6)$ \\
\hline MHI-5 sum score $[M(S D)]$ & $6.68(3.4)$ & $6.68(3.4)$ & $6.27(3.3)$ & $7.26(3.8)$ \\
\hline AUDIT-C sum score $[M(S D)]$ & $4.38(2.5)$ & $4.20(2.4)$ & $5.74(2.4)$ & $6.29(2.6)$ \\
\hline \multicolumn{5}{|l|}{ ASQ subscale sum score $[M(S D)]$} \\
\hline Concealing & $29.24(6.1)$ & $29.12(6.0)$ & $29.95(6.3)$ & $30.87(6.3)$ \\
\hline Adjusting & $16.42(4.1)$ & $16.43(4.1)$ & $16.62(4.0)$ & $15.85(4.6)$ \\
\hline Tolerating & $20.58(4.1)$ & $20.68(4.0)$ & $19.87(4.3)$ & $19.40(4.6)$ \\
\hline
\end{tabular}

Note. $n$ : valid values; $M$ : mean; $S D$ : standard deviation; Non-problematic gamblers: $0-1$ DSM-5 criteria; Problematic gamblers: 2-3 DSM-5 criteria; Pathological gamblers: $\geq 4$ DSM-5 criteria; MHI-5: Mental Health Inventory; AUDIT-C: Alcohol Use Disorder Identification Test - Consumption; ASQ: Affective Style Questionnaire. 
Table 2. Linear regression analysis with Stinchfield sum score as dependent variable

\begin{tabular}{|c|c|c|c|c|c|c|}
\hline & & $B$ & $S E(B \mathrm{~s})$ & $\beta$ & $p$ & {$[95 \% \mathrm{CI}]$} \\
\hline \multirow[t]{5}{*}{ Concealing } & Scale & 0.007 & 0.008 & 0.018 & .392 & {$[-0.009$ to 0.024$]$} \\
\hline & Sex & 1.063 & 0.127 & 0.185 & $<.001$ & [0.814 to 1.312$]$ \\
\hline & MB & 1.044 & 0.125 & 0.175 & $<.001$ & [0.800 to 1.289$]$ \\
\hline & AUDIT-C & 0.137 & 0.021 & 0.138 & $<.001$ & [0.096 to 0.179$]$ \\
\hline & MHI-5 & 0.102 & 0.016 & 0.137 & $<.001$ & [0.071 to 0.133$]$ \\
\hline \multirow[t]{5}{*}{ Adjusting } & Scale & -0.035 & 0.014 & -0.058 & .014 & {$[-0.063$ to -0.007$]$} \\
\hline & Sex & 1.129 & 0.127 & 0.197 & $<.001$ & [0.880 to 1.378$]$ \\
\hline & $\mathrm{MB}$ & 1.049 & 0.124 & 0.176 & $<.001$ & [0.805 to 1.293$]$ \\
\hline & AUDIT-C & 0.136 & 0.021 & 0.137 & $<.001$ & [0.095 to 0.178$]$ \\
\hline & MHI-5 & 0.083 & 0.018 & 0.111 & $<.001$ & [0.048 to 0.118$]$ \\
\hline \multirow[t]{5}{*}{ Tolerating } & Scale & -0.041 & 0.013 & -0.069 & .001 & {$[-0.067$ to -0.016$]$} \\
\hline & Sex & 1.069 & 0.125 & 0.187 & $<.001$ & [0.824 to 1.315$]$ \\
\hline & $\mathrm{MB}$ & 1.020 & 0.124 & 0.171 & $<.001$ & [0.776 to 1.264$]$ \\
\hline & AUDIT-C & 0.133 & 0.021 & 0.134 & $<.001$ & [0.092 to 0.175$]$ \\
\hline & MHI-5 & 0.090 & 0.016 & 0.121 & $<.001$ & [0.058 to 0.122$]$ \\
\hline
\end{tabular}

Note. Sex: $0=$ female, $1=$ male; Migration background $(\mathrm{MB})$ : $0=$ no, $1=$ yes; AUDIT-C: Alcohol Use Disorder Identification Test Consumption (score: 0-11); MHI-5: Mental Health Inventory (score: 0-20); $B$ : regression coefficient; SE: standard error; CI: confidence interval.

MHI-5 sum score were included in the linear and multinomial regression analyses to control the influence of these factors.

\section{Dimensional analysis}

The results of the linear regression analysis are shown in Table 2. After adjusting the data for the covariates, there was no significant association between affirmed Stinchfield items and the subscale "Concealing" in any model. However, the analysis still revealed a significant correlation between the Stinchfield sum score and the subscales "Adjusting" $(p=.014)$ and "Tolerating" $(p=.001)$. A lower score on these subscales is related to a higher number of affirmed Stinchfield items.

\section{Categorical analyses}

We performed separate multinomial logistic regression analyses for each subscale of the ASQ and regression coefficients (interpreted as CORs).

Table 3 shows the results of the subscale "Concealing." Having included the covariates, no significant group differences were found, but a statistical tendency could be observed between pathological and non-problematic gamblers $(p=.084)$.

The results of the subscale "Adjusting" are shown in Table 4. No significant differences in CORs could be found between problematic gamblers and non-problematic gamblers, but a statistical tendency could be observed $(p=.079)$. The comparison of pathological gamblers with nonproblematic gamblers revealed a significant lower COR for the subscale sum score $(p=.011)$. Subjects were more likely to be classified as a pathological gambler when they scored lower on the subscale "Adjusting." There were no significant differences between the groups of pathological and problematic gamblers.

Table 5 shows the results of the third subscale "Tolerating." Comparing problematic with non-problematic gamblers, the data revealed a significant lower COR for the subscale sum score $(p=.005)$. Comparing pathological with non-problematic gamblers, the COR was significantly lower, even when all other covariates were controlled $(p=.010)$. In both cases, a lower score on the subscale "Tolerating" led to a higher possibility to be classified as a problematic or as a pathological gambler. No significant

Table 3. Multinomial logistic regression analysis for the ER strategy "Concealing" among non-problematic, problematic, and pathological gamblers

\begin{tabular}{|c|c|c|c|c|c|c|c|c|c|}
\hline & \multicolumn{3}{|c|}{$\begin{array}{l}\text { Problematic gamblers vs. } \\
\text { non-problematic gamblers }\end{array}$} & \multicolumn{3}{|c|}{$\begin{array}{l}\text { Pathological gamblers vs. } \\
\text { non-problematic gamblers }\end{array}$} & \multicolumn{3}{|c|}{$\begin{array}{l}\text { Pathological gamblers vs. } \\
\text { problematic gamblers }{ }^{\mathrm{a}}\end{array}$} \\
\hline & $\operatorname{Exp}(B)^{\mathrm{b}}$ & {$[95 \% \mathrm{CI}]$} & $p$ value & $\operatorname{Exp}(B)^{\mathrm{b}}$ & {$[95 \% \mathrm{CI}]$} & $p$ value & $\operatorname{Exp}(B)^{\mathrm{b}}$ & {$[95 \% \mathrm{CI}]$} & $p$ value \\
\hline Concealing & 1.00 & [0.98-1.02] & .872 & 1.02 & [1.00-1.05] & .084 & 1.02 & [0.99-1.05] & .200 \\
\hline Sex & 5.71 & [3.72-8.76] & $<.001$ & 13.04 & [6.57-25.89] & $<.001$ & 2.28 & [1.03-5.08] & .043 \\
\hline $\mathrm{MB}$ & 2.10 & {$[1.61-2.75]$} & $<.001$ & 2.74 & {$[2.02-3.73]$} & $<.001$ & 1.31 & [0.89-1.91] & .169 \\
\hline AUDIT-C & 1.23 & [1.17-1.29] & $<.001$ & 1.33 & [1.25-1.41] & $<.001$ & 1.09 & [1.01-1.17] & .029 \\
\hline MHI-5 & 1.01 & [0.97-1.05] & .673 & 1.10 & [1.06-1.15] & $<.001$ & 1.09 & [1.04-1.15] & .001 \\
\hline
\end{tabular}

Note. Sex: $0=$ female, $1=$ male; Migration background (MB): $0=$ no, $1=$ yes; AUDIT-C: Alcohol Use Disorder Identification Test Consumption (score: 0-11); MHI-5: Mental Health Inventory (score: 0-20); CI: confidence interval; ER: emotion regulation.

${ }^{a}$ The last of the two compared categories is always the reference category. ${ }^{b} \operatorname{Exp}(B)=$ regression coefficients are interpreted in terms of conditional odds ratios. 
Table 4. Multinomial logistic regression analysis for the ER strategy "Adjusting” among non-problematic, problematic, and pathological gamblers

\begin{tabular}{|c|c|c|c|c|c|c|c|c|c|}
\hline & \multicolumn{3}{|c|}{$\begin{array}{l}\text { Problematic gamblers vs. } \\
\text { non-problematic gamblers }\end{array}$} & \multicolumn{3}{|c|}{$\begin{array}{l}\text { Pathological gamblers vs. } \\
\text { non-problematic gamblers }\end{array}$} & \multicolumn{3}{|c|}{$\begin{array}{l}\text { Pathological gamblers vs. } \\
\text { problematic gamblers }\end{array}$} \\
\hline & $\operatorname{Exp}(B)^{\mathrm{b}}$ & {$[95 \% \mathrm{CI}]$} & $p$ value & $\operatorname{Exp}(B)^{\mathrm{b}}$ & {$[95 \% \mathrm{CI}]$} & $p$ value & $\operatorname{Exp}(B)^{\mathrm{b}}$ & {$[95 \% \mathrm{CI}]$} & $p$ value \\
\hline Adjusting & 0.97 & [0.94-1.00] & .079 & 0.95 & [0.91-0.99] & .011 & 0.98 & [0.93-1.03] & .400 \\
\hline Sex & 5.95 & [3.87-9.15] & $<.001$ & 14.29 & [7.19-28.40] & $<.001$ & 2.40 & [1.08-5.35] & .032 \\
\hline $\mathrm{MB}$ & 2.12 & [1.62-2.77] & $<.001$ & 2.79 & [2.05-3.79] & $<.001$ & 1.31 & [0.90-1.92] & .158 \\
\hline AUDIT-C & 1.22 & [1.17-1.29] & $<.001$ & 1.33 & [1.25-1.41] & $<.001$ & 1.09 & [1.01-1.17] & .026 \\
\hline MHI-5 & 0.99 & [0.95-1.04] & .730 & 1.08 & [1.03-1.13] & .002 & 1.08 & [1.02-1.15] & .008 \\
\hline
\end{tabular}

Note. Sex: $0=$ female, $1=$ male; Migration background (MB): $0=$ no, $1=$ yes; AUDIT-C: Alcohol Use Disorder Identification Test Consumption (score: 0-11); MHI-5: Mental Health Inventory (score: 0-20); CI: confidence interval; ER: emotion regulation.

${ }^{a}$ The last of the two compared categories is always the reference category. ${ }^{b}$ Regression coefficients are interpreted in terms of conditional odds ratios.

Table 5. Multinomial logistic regression analysis for the ER strategy "Tolerating" among non-problematic, problematic, and pathological gamblers

\begin{tabular}{|c|c|c|c|c|c|c|c|c|c|}
\hline & \multicolumn{3}{|c|}{$\begin{array}{l}\text { Problematic gamblers vs. } \\
\text { non-problematic gamblers }\end{array}$} & \multicolumn{3}{|c|}{$\begin{array}{l}\text { Pathological gamblers vs. } \\
\text { non-problematic gamblers }\end{array}$} & \multicolumn{3}{|c|}{$\begin{array}{l}\text { Pathological gamblers vs. } \\
\text { problematic gamblers }^{\mathrm{a}}\end{array}$} \\
\hline & $\operatorname{Exp}(B)^{\mathrm{b}}$ & {$[95 \% \mathrm{CI}]$} & $p$ value & $\operatorname{Exp}(B)^{\mathrm{b}}$ & {$[95 \% \mathrm{CI}]$} & $p$ value & $\operatorname{Exp}(B)^{\mathrm{b}}$ & {$[95 \% \mathrm{CI}]$} & $p$ value \\
\hline Tolerating & 0.96 & [0.93-0.99] & .005 & 0.95 & [0.92-0.99] & .010 & 1.00 & [0.95-1.04] & .876 \\
\hline Sex & 5.69 & [3.71-8.73] & $<.001$ & 13.32 & [6.71-26.43] & $<.001$ & 2.34 & [1.05-5.20] & .037 \\
\hline MB & 2.06 & [1.58-2.70] & $<.001$ & 2.71 & [2.00-3.68] & $<.001$ & 1.31 & [0.90-1.92] & .159 \\
\hline AUDIT-C & 1.22 & [1.16-1.28] & $<.001$ & 1.33 & [1.25-1.41] & $<.001$ & 1.09 & [1.01-1.17] & .027 \\
\hline MHI-5 & 1.00 & [0.96-1.04] & .847 & 1.09 & [1.04-1.14] & $<.001$ & 1.09 & [1.04-1.15] & .001 \\
\hline
\end{tabular}

Note. Sex: $0=$ female, $1=$ male; Migration background (MB): 0: =no, 1=yes; AUDIT-C: Alcohol Use Disorder Identification Test Consumption (score: 0-11); MHI-5: Mental Health Inventory (score: 0-20); CI: confidence interval; ER: emotion regulation.

${ }^{a}$ The last of the two compared categories is always the reference category. ${ }^{\text {}}$ Regression coefficients are interpreted in terms of conditional odds ratios.

differences could be identified for this ER strategy by comparing problematic with pathological gamblers.

\section{DISCUSSION}

To our knowledge, this is the first study to examine ER strategies in a systematically and proactively recruited sample of gamblers. The aim of this study was to examine deficits in the use of functional ER strategies in a large and unselected sample of young individuals. We compared the use of three different ER strategies between self-reported pathological, problematic, and non-problematic gamblers.

As hypothesized, we found significant associations between self-reported gambling-related problems and ER strategies. The negative correlation between the ER strategies "Adjusting" and "Tolerating" and the number of affirmed Stinchfield-items suggests that a lack or a maladaptive use of these two strategies is associated with the number of DSM-5 symptoms. Even when data were adjusted for sociodemographic characteristics, mental health and alcohol use, the significant effect of these two ER strategies on gambling behavior was stable.

Furthermore, the multinomial logistic regression analyses provided detailed information on group differences for specific ER strategies. Concerning response-focused strategies, there was no significant difference in the use of the ER strategy "Concealing" between the groups. Even though there was no significant difference between pathological and non-problematic gamblers, a statistical tendency could be observed, and the descriptive statistic revealed that individuals with a higher score met more DSM-5 criteria. As there was no significance, we could not confirm our hypothesis. However, pathological gamblers tend to suppress their emotions more than non-pathological gamblers. This finding is in line with other studies showing that concealing or suppressing emotions is dysfunctional to regulate emotions (Levin et al., 2012; Wong et al., 2013).

Gross and John (2003) demonstrated that reappraisal is a much more functional strategy to regulate emotions than suppression. "Adjusting" means cognitively adapting to a new situation in order to change the emotional appraisal of the situation before an emotional response is activated, similar to reappraising emotions. Our results show that subjects who reported lower skills in this antecedentfocused strategy were more likely to be classified as pathological gamblers, which confirm our initial hypothesis. Indeed, no group difference could be found in our data between problematic gamblers on a subthreshold level (<4 DSM-5 criteria) and non-problematic gamblers. 
This finding supports the suggestion that difficulties in regulating emotions in advance by use of this cognitive strategy could be a risk factor especially for pathological gambling. On the other hand, the functional use of "Adjusting" was identified to be an independent protective factor for pathological gambling.

The data revealed group differences between problematic and non-problematic gamblers and pathological and nonproblematic gamblers regarding the ability to tolerate own negative emotions. Individuals with problematic and/or pathological gambling behavior reported less use of the ER strategy "Tolerating," so the hypothesis could be confirmed. The lack of an accepting attitude toward negative emotions could be identified as a risk factor to be a problematic or pathological gambler, even when the influence of other possible factors was controlled. No difference for the ability to tolerate negative emotions between individuals with the diagnosis of a gambling disorder and individuals meeting the criteria on a subthreshold level could be shown. Therefore, one could suggest that acceptance might be a helpful strategy to prevent gambling-related problems on a subthreshold level. Tolerating the own emotions reduces the probability to show pathological gambling behavior. In addition, lacking this ability increases the probability to have gambling-related problems. These findings are similar to the results by Berking et al. (2011), who identified the lack of tolerance as the most important risk factor for relapse in alcohol-dependent patients. The comparison between individuals classified as pathological gamblers and non-problematic gamblers demonstrates that a maladaptive use of the ER strategies "Adjusting" and "Tolerating" is a risk factor for pathological gambling. Furthermore, "Tolerating" is an independent risk factor even on an advanced level of gambling-related problems. The results of both the dimensional as well as the categorical analyses suggest that the skill to tolerate own negative emotions is a very constant protective factor for gamblingrelated problems as well as for meeting the DSM-5 criteria for a gambling disorder. Having a comfort and accepting attitude to arousing emotional experience and a strong tolerance of distress seemed to be associated with less criteria for gambling-related problems.

Interestingly, we found a difference between individuals with and without a MB regarding their ability to regulate emotions functionally. The described significant differences were stable in any regression model and they could not be better explained by other factors. The studies found a strong association between gambling disorder and MB (Petry et al., 2003) that cannot be explained by sociodemographic characteristics and gambling preferences (Kastirke, Rumpf, John, Bischof, \& Meyer, 2014). Besides a significantly higher prevalence rate of pathological gambling in the population of individuals with a MB, this study identified that individuals with a MB showed lesser use of the strategies "Adjusting" and "Tolerating" and an increased use of the strategy "Concealing" compared to individuals without a MB.

\section{Limitations}

Despite many advantages, some limitations of this study have to be mentioned. Although the large sample consisted of proactively recruited unselected participants, our results refer to vocational students only and can thus not be generalized to the general population.

Furthermore, the study is limited by the use of the Stinchfield questionnaire that is a self-reporting instrument, which could possibly overestimate the prevalence of pathological gambling (Stinchfield, 2002).

Another point of discussion is the ASQ, which covers three different strategies of regulating emotions and which was chosen as measurement for ER because of its comprehensiveness and good internal consistence. We have used the validated German version of the ASQ, which could confirm the factor structure with only minor changes concerning two items (Graser et al., 2012). Although it has been used in different studies, there is still no available validation of the German translation of the ASQ on the basis of a clinical sample or with other populations. Furthermore, the ASQ concentrates on the regulation of negative emotions exclusively, disregarding the regulation of positive emotions as an important aspect of psychopathological models of addiction disorders (Cheetham et al., 2010). In their review, Cheetham et al. (2010) postulated that a high positive affect plays a major role especially in the early stages of an addictive disorder, whereas a low affect becomes relevant in later stages. On that account, further investigations are needed with regard to the regulation of positive emotions in the population of gamblers as well.

Furthermore, due to limited time to complete the survey, we were unable to include a questionnaire for measuring depression specifically. We therefore used the MHI-5 as a brief instrument to measure mental health.

One requirement for participation and filling out the questionnaires was a sufficient knowledge of the German language, so we could not include migrants with insufficient language skills. However, we are unsure whether all participants understood each question correctly.

\section{Conclusion and implications for clinical practice}

This study provides important new aspects regarding the association of ER strategies and pathological gambling. Our findings highly suggest that training of adaptive ER strategies is a candidate treatment that could potentially be integrated in psychotherapy for patients with gambling problems. Therefore, it will be necessary to further prove its effectiveness in a randomized controlled study and to investigate whether pathological gamblers could benefit from a therapeutic intervention that improves their ER skills. One possible treatment option could be the Dialectical Behavioral Therapy (DBT) developed by Linehan (2018). DBT is a form of cognitive behavioral therapy and works toward supporting patients to increase their ER abilities. A skill training for ER could be a helpful concept for individuals with a behavioral addiction like pathological gambling. Another option could be the Acceptance and Commitment Therapy (Hayes, Luoma, Bond, Masuda, \& Lillis, 2006), which integrates acceptance, mindfulness, and behavior-change strategies as psychological interventions to increase psychological flexibility. We found that tolerating negative emotions plays an important role even on a subthreshold level. Therefore, the data support the inclusion of 
a training into prevention measures that aim to develop a tolerating attitude toward unpleasant emotions in order to intervene at an early stage of the development of gamblingrelated problems

Funding sources: The project was supported by the Ministry of Social Affairs, Health, Science and Equality of the Federal State of Schleswig-Holstein.

Authors' contribution: SO: data gathering, statistical analysis, interpretation of findings, and preparation of manuscript draft. $\mathrm{AB}$ and GB: study concept and design, statistical analysis, and interpretation of findings. BB: Data gathering. H-JR: study supervision, study concept and design, and obtained funding. All authors had full access to all data in the study and take responsibility for the integrity of the data and the accuracy of the data analysis.

Conflict of interest: The authors declare no conflict of interest.

\section{REFERENCES}

Aldao, A., Jazaieri, H., Goldin, P. R., \& Gross, J. J. (2014). Adaptive and maladaptive emotion regulation strategies: Interactive effects during CBT for social anxiety disorder. Journal of Anxiety Disorders, 28(4), 382-389. doi:10.1016/j.janxdis. 2014.03.005

Aldao, A., Nolen-Hoeksema, S., \& Schweizer, S. (2010). Emotionregulation strategies across psychopathology: A meta-analytic review. Clinical Psychology Review, 30(2), 217-237. doi:10.1016/j.cpr.2009.11.004

American Psychiatric Association [APA]. (2013). Diagnostic and statistical manual of mental disorders (5th ed.). Arlington, VA: American Psychiatric Association.

Baker, T. B., Piper, M. E., McCarthy, D. E., Majeskie, M. R., \& Fiore, M. C. (2004). Addiction motivation reformulated: An affective processing model of negative reinforcement. Psychological Review, 111(1), 33-51. doi:10.1037/0033-295X.111.1.33

Berking, M., Margraf, M., Ebert, D., Wupperman, P., Hofmann, S. G., \& Junghanns, K. (2011). Deficits in emotion-regulation skills predict alcohol use during and after cognitive-behavioral therapy for alcohol dependence. Journal of Consulting and Clinical Psychology, 79(3), 307-318. doi:10.1037/a0023421

Berking, M., \& Wupperman, P. (2012). Emotion regulation and mental health: Recent findings, current challenges, and future directions. Current Opinion in Psychiatry, 25(2), 128-134. doi:10.1097/YCO.0b013e3283503669

Berwick, D. M., Murphy, J. M., Goldman, P. A., Ware, J. E., Barsky, A. J., \& Weinstein, M. C. (1991). Performance of a 5-item Mental-Health Screening-Test. Medical Care, 29(2), 169-176. doi:10.1097/00005650-199102000-00008

Bush, K., Kivlahan, D. R., McDonell, M. B., Fihn, S. D., \& Bradley, K. A. (1998). The AUDIT Alcohol Consumption Questions (AUDIT-C). An effective brief screening test for problem drinking. Archives of Internal Medicine, 158(16), 1789-1795. doi:10.1001/archinte.158.16.1789
Bydlowski, S., Corcos, M., Jeammet, P., Paterniti, S., Berthoz, S., Laurier, C., Chambry, J., \& Consoli, S. M. (2005). Emotionprocessing deficits in eating disorders. International Journal of Eating Disorders, 37(4), 321-329. doi:10.1002/eat.20132

Campell-Sills, L., \& Barlow, D. H. (2007). Incorparating emotion regulation into conceptualizations and treatments of anxiety and mood disorders. In J. J. Gross (Ed.), Handbook of emotion regulation (pp. 542-559). New York, NY: Guilford Press.

Cheetham, A., Allen, N. B., Yucel, M., \& Lubman, D. I. (2010). The role of affective dysregulation in drug addiction. Clinical Psychology Review, 30(6), 621-634. doi:10.1016/j.cpr.2010. 04.005

Dybek, I., Bischof, G., Grothues, J., Reinhardt, S., Meyer, C., Hapke, U., John, U., Broocks, A., Hohagen, F., \& Rumpf, H.-J. (2006). The reliability and validity of the Alcohol Use Disorders Identification Test (AUDIT) in a German general practice population sample. Journal of Studies on Alcohol, 67(3), 473-481. doi:10.15288/jsa.2006.67.473

Estevez, A., Jauregui, P., Sanchez-Marcos, I., Lopez-Gonzalez, H., \& Griffiths, M. D. (2017). Attachment and emotion regulation in substance addictions and behavioral addictions. Journal of Behavioral Addictions, 6(4), 534-544. doi:10.1556/2006.6. 2017.086

Fox, H. C., Axelrod, S. R., Paliwal, P., Sleeper, J., \& Sinha, R. (2007). Difficulties in emotion regulation and impulse control during cocaine abstinence. Drug and Alcohol Dependence, 89(2-3), 298-301. doi:10.1016/j.drugalcdep.2006.12.026

Fox, H. C., Hong, K. A., \& Sinha, R. (2008). Difficulties in emotion regulation and impulse control in recently abstinent alcoholics compared with social drinkers. Addictive Behaviors, 33(2), 388-394. doi:10.1016/j.addbeh.2007.10.002

Gould, W. (2000). Interpreting logistic regression in all its forms. Stata Technical Bulletin, 53, 19-29.

Graser, J., Bohn, C., Kelava, A., Schreiber, F., Hofmann, S. G., \& Stangier, U. (2012). The Affective Style Questionnaire (ASQ): German adaptation and validity. Diagnostica, 58(2), 100-111. doi:10.1026/0012-1924/a000056

Gross, J. J. (1998). The emerging field of emotion regulation: An integrative review. Review of General Psychology, 2(3), 271-299. doi:10.1037/1089-2680.2.3.271

Gross, J. J., \& John, O. P. (2003). Individual differences in two emotion regulation processes: Implications for affect, relationships, and well-being. Journal of Personality and Social Psychology, 85(2), 348-362. doi:10.1037/0022-3514.85.2.348

Gross, J. J., \& Munoz, R. F. (1995). Emotion regulation and mental-health. Clinical Psychology-Science and Practice, 2(2), 151-164. doi:10.1111/j.1468-2850.1995.tb00036.x

Gross, J. J., \& Thompson, R. A. (2007). Emotion regulation: Conceptual foundations. In J. J. Gross (Ed.), Handbook of emotion regulation (pp. 3-24). New York, NY: Guilford Press.

Harrison, A., Sullivan, S., Tchanturia, K., \& Treasure, J. (2010). Emotional functioning in eating disorders: Attentional bias, emotion recognition and emotion regulation. Psychological Medicine, 40(11), 1887-1897. doi:10.1017/S003329171 0000036

Hayes, S. C., Luoma, J. B., Bond, F. W., Masuda, A., \& Lillis, J. (2006). Acceptance and commitment therapy: Model, processes and outcomes. Behaviour Research and Therapy, 44(1), 1-25. doi:10.1016/j.brat.2005.06.006

Hofmann, S. G., \& Kashdan, T. B. (2010). The Affective Style Questionnaire: Development and psychometric properties. 
Journal of Psychopathology and Behavioral Assessment, 32(2), 255-263. doi:10.1007/s10862-009-9142-4

Kapsomenakis, A., Simos, P. G., Konstantakopoulos, G., \& Kasselimis, D. S. (2018). In search of executive impairment in pathological gambling: A neuropsychological study on nontreatment seeking gamblers. Journal of Gambling Studies, 34(4), 1327-1340. doi:10.1007/s10899-018-9758-y

Kassel, J. D., Veilleux, J. C., Wardle, M. C., Yates, M. C., Greenstein, J. E., Evatt, D. P., \& Roesch, L. L. (2007). Negative affect and addiction. In M. Al'Absi (Ed.), Stress and addiction: Biological and psychological mechanisms (pp. 171-189). London, UK: Elsevier Science.

Kastirke, N., Rumpf, H. J., John, U., Bischof, A., \& Meyer, C. (2014). Demographic risk factors and gambling preference may not explain the high prevalence of gambling problems among the population with migration background Results from a German nationwide survey. Journal of Gambling Studies, 31(3), 741-7577. doi:10.1007/s10899014-9459-0

Khantzian, E. J. (1985). The self-medication hypothesis of addictive disorders - Focus on heroin and cocaine dependence. American Journal of Psychiatry, 142(11), 1259-1264. doi:10.1176/ajp.142.11.1259

Kopera, M., Trucco, E. M., Jakubczyk, A., Suszek, H., Michalska, A., Majewska, A., Szejko, N., Łoczewska, A., Krasowska, A., Klimkiewicz, A., Brower, K. J., Zucker, R. A., \& Klimkiewicz, A. (2018). Interpersonal and intrapersonal emotional processes in individuals treated for alcohol use disorder and non-addicted healthy individuals. Addictive Behaviors, 79, 8-13. doi:10.1016/j.addbeh.2017.12.006

Lesieur, H. R., \& Blume, S. B. (1987). The South Oaks Gambling Screen (SOGS) - A new instrument for the identification of pathological gamblers. American Journal of Psychiatry, 144(9), 1184-1188. doi:10.1176/ajp.144.9.1184

Levin, M. E., Lillis, J., Seeley, J., Hayes, S. C., Pistorello, J., \& Biglan, A. (2012). Exploring the relationship between experiential avoidance, alcohol use disorders, and alcohol-related problems among first-year college students. Journal of American College Health, 60(6), 443-448. doi:10.1080/07448481. 2012.673522

Levine, D., Marziali, E., \& Hood, J. (1997). Emotion processing in borderline personality disorders. The Journal of Nervous and Mental Disease, 185(4), 240-246. doi:10.1097/00005053199704000-00004

Linehan, M. M. (2018). Cognitive-behavioral treatment of borderline personality disorder. New York, NY: Guilford Press.

McRae, K., Ochsner, K. N., Mauss, I. B., Gabrieli, J. J., \& Gross, J. J. (2008). Gender differences in emotion regulation: An fMRI study of cognitive reappraisal. Group processes \& Intergroup Relations, 11(2), 143-162. doi:10.1177/1368430207088035

Navas, J. F., Verdejo-García, A., López-Gómez, M., Maldonado, A., \& Perales, J. C. (2016). Gambling with rose-tinted glasses on: Use of emotion-regulation strategies correlates with dysfunctional cognitions in gambling disorder patients. Journal of Behavioral Addictions, 5(2), 271-281. doi:10.1556/ 2006.5.2016.040

Nolen-Hoeksema, S., \& Aldao, A. (2011). Gender and age differences in emotion regulation strategies and their relationship to depressive symptoms. Personality and Individual Differences, 51(6), 704-708. doi:10.1016/j.paid.2011.06.012

Nolen-Hoeksema, S., Stice, E., Wade, E., \& Bohon, C. (2007). Reciprocal relations between rumination and bulimic, substance abuse, and depressive symptoms in female adolescents. Journal of Abnormal Psychology, 116(1), 198-207. doi:10.1037/0021-843X.116.1.198

Petry, N. M., Armentano, C., Kuoch, T., Norinth, T., \& Smith, L. (2003). Gambling participation and problems among South East Asian refugees to the United States. Psychiatric Services, 54(8), 1142-1148. doi:10.1176/appi.ps.54.8.1142

Reinert, D. F., \& Allen, J. P. (2002). The Alcohol Use Disorders Identification Test (AUDIT): A review of recent research. Alcoholism: Clinical and Experimental Research, 26(2), 272-279. doi:10.1111/j.1530-0277.2002.tb02534.x

Rottenberg, J., Gross, J. J., \& Gotlib, I. H. (2005). Emotion context insensitivity in major depressive disorder. Journal of Abnormal Psychology, 114(4), 627-639. doi:10.1037/0021-843X. 114.4.627

Rumpf, H.-J., Meyer, C., Hapke, U., \& John, U. (2001). Screening for mental health: Validity of the MHI-5 using DSM-IV Axis I psychiatric disorders as gold standard. Psychiatry Research, 105(3), 243-253. doi:10.1016/S0165-1781(01) 00329-8

Stinchfield, R. (2002). Reliability, validity, and classification accuracy of the South Oaks Gambling Screen (SOGS). Addictive Behaviors, 27(1), 1-19. doi:10.1016/S0306-4603(00)00158-1

Stinchfield, R. (2003). Reliability, validity, and classification accuracy of a measure of DSM-IV diagnostic criteria for pathological gambling. American Journal of Psychiatry, 160(1), 180-182. doi:10.1176/appi.ajp.160.1.180

Werner, K., \& Gross, J. J. (2010). Emotion regulation and psychopathology: A conceptual framework. In A. M. Kring \& D. M. Sloan (Eds.), Emotion regulation and psychopathology: A transdiagnostic approach to etiology and treatment (pp. 13-37). New York, NY: Guilford Press.

Williams, A. D., Grisham, J. R., Erskine, A., \& Cassedy, E. (2012). Deficits in emotion regulation associated with pathological gambling. British Journal of Clinical Psychology, 51(2), 223-238. doi:10.1111/j.2044-8260.2011.02022.x

Wong, C. F., Silva, K., Kecojevic, A., Schrager, S. M., Bloom, J. J., Iverson, E., \& Lankenau, S. E. (2013). Coping and emotion regulation profiles as predictors of nonmedical prescription drug and illicit drug use among high-risk young adults. Drug and Alcohol Dependence, 132(1-2), 165-171. doi:10.1016/j.drugalcdep.2013.01.024 